\title{
Outcome of Soft-tissue Reconstruction in the Setting of Combined Preoperative and Intraoperative Radiotherapy for Extremity Soft-tissue Sarcomas
}

\author{
RACHEL L. HONIG ${ }^{1}$, MEAGAN E. TIBBO ${ }^{1}$, KATHERINE E. MALLETT ${ }^{1}$, KARIM BAKRI $^{2}$, SAFIA K. AHMED ${ }^{3}$, \\ IVY A. PETERSEN ${ }^{3}$, PETER S. ROSE ${ }^{1}$, STEVEN L. MORAN $^{2}$ and MATTHEW T. HOUDEK ${ }^{1}$ \\ ${ }^{1}$ Department of Orthopedic Surgery, Mayo Clinic, Rochester, MN, U.S.A.; \\ ${ }^{2}$ Division of Plastic and Reconstructive Surgery, Mayo Clinic, Rochester, MN, U.S.A.; \\ ${ }^{3}$ Department of Radiation Oncology, Mayo Clinic, Rochester, MN, U.S.A.
}

\begin{abstract}
Background/Aim: Reconstruction for soft-tissue sarcomas is complex and often uses soft-tissue flaps. To preserve critical structures, intraoperative radiotherapy (IORT) can be used to boost the total dose to these critical structures and close margins; however, there are limited data on the outcome of softtissue reconstruction in patients treated with IORT. Patients and Methods: Twenty patients received IORT with soft-tissue flap coverage. There were 14 tumors of the lower extremities and six of the upper, including seven free-flaps and 13 pedicle flaps. Mean preoperative and IORT doses were 49.4 Gy and 10.4 Gy, respectively, with a mean total dose of 59.8 Gy. Results: Seven (35\%) patients had a complication, most commonly an infection $(n=4,27 \%)$. Total flap loss occurred in one treated with pedicle flap. Four (20\%) patients suffered a radiation-associated fracture. At the final follow-up, the mean Musculoskeletal Tumor Society Score was $75 \pm 11 \%$. Conclusion: Complications and postoperative fractures were common with IORT, however, there were no cases requiring amputation.
\end{abstract}

Soft-tissue sarcomas are rare forms of cancer which typically occur in the extremities $(1,2)$. Currently, limb-salvage surgery with wide surgical excision is the standard treatment for patients with extremity soft-tissue sarcomas. Radiotherapy is often used to reduce the rate of local recurrence and is often used in the neoadjuvant (preoperative) or adjuvant (postoperative) setting

This article is freely accessible online.

Correspondence to: Matthew T. Houdek, MD, Department of Orthopedic Surgery, 200 First Street S.W., Rochester, MN 55905, U.S.A. Tel: +1 5072848531, Fax: +1 5072664234, e-mail: houdek.matthew@mayo.edu

Key Words: Intraoperative radiotherapy, IORT, limb salvage, softtissue reconstruction, flap.
$(1,3-5)$. While advantageous in assisting with margin control and reduce the risk of local recurrence, neoadjuvant radiation is not without complications, namely wound complications and infection (4-6).

Intraoperative radiotherapy (IORT) can be used to assist with margin control by delivering a boost of radiotherapy to the tumor bed (often a dose of 10-12 Gy), when these tumors are in close proximity to vital neurovascular structures or if the margin of resection is within several millimeters of the sarcoma $(7,8)$. Following surgical resection, soft-tissue reconstruction in the form of a free flap or a local pedicled flap is often needed to achieve limb salvage. Previous series have examined softtissue reconstruction in the setting of preoperative radiotherapy $(5,6,9,10)$. However, there are limited data available to examine the outcome of soft-tissue reconstruction in the setting of IORT. As such, the purpose of this study was to examine the outcome of soft-tissue reconstruction in the setting of combined neoadjuvant radiotherapy and an IORT boost.

\section{Patients and Methods}

After obtaining Institutional Review Board approval (IRB Protocol: 18-011231), we reviewed 20 patients (11 female, nine male) (Table I), with a mean age and body mass index of $58 \pm 19$ years and $30.5 \pm 6.5$ $\mathrm{kg} / \mathrm{m}^{2}$, undergoing resection of an extremity soft-tissue sarcoma treated with limb salvage surgery through a planned wide local excision, IORT and immediate soft-tissue reconstruction. There were $14(70 \%)$ lower extremity and six (30\%) upper extremity tumors treated with six $(30 \%)$ free flaps and $14(70 \%)$ rotational/pedicle flaps. The free flaps included the latissimus in two, anterior lateral thigh in one, gracilis in one, radial forearm in one, and transverse rectus abdominus flap in one. Pedicled flaps included gastrocnemius in four, random pattern fasciocutaneous flaps in two, radial forearm in two, sartorius in two, sural artery in one, latissimus in one, ulnar artery flap in one, and pectoralis major in one.

Oncological diagnoses included undifferentiated pleomorphic sarcoma in eight, myxofibrosarcoma in four, myxoid liposarcoma in three, spindle-cell sarcoma/rhabdomyosarcoma in three, and 
synovial sarcoma in two. The mean tumor size and volume were $8 \pm 7 \mathrm{~cm}$ and $728 \pm 1,400 \mathrm{~cm}^{3}$, respectively.

All patients received preoperative radiotherapy with a boost of IORT given to the tumor bed after the margins were evaluated by frozen histology. The dose of IORT was given to the area of the closest margin. The margin status included 19 negative and one microscopically positive (R1) margin, with the mean negative margin distance of $3.5 \pm 3.5 \mathrm{~mm}$. The location of the close margin included the periosteum in seven, deep fascia in five, adventitia in three, epineurium in three, and peritenon in two.

The mean preoperative and IORT doses were $49.4 \pm 1.5 \mathrm{~Gy}$ and $10.4 \pm 1.1 \mathrm{~Gy}$, for the mean total dose of radiotherapy of $59.8 \pm 1.9$ Gy. In addition, 11 patients received chemotherapy prior to surgery. The IORT was given prior to flap in-setting. In patients undergoing a free-flap procedure, the anastomosis was made outside the field of the IORT; however, the vessels were likely in the field of the preoperative radiotherapy.

Patients were followed routinely with a physical examination and local imaging of the operative bed to assess for local tumor recurrence and with a computed tomographic scan of the lungs to evaluate for metastatic disease every 3-4 months for the first 2 years postoperative, every 6 months for years $2-5$, and yearly for years 5 10. The mean follow-up was $5 \pm 3$ years.

Continuous variables were analyzed using unpaired Student's $t$ test, and categorical variables were compared with Fisher's exact test and odds ratios. Functional outcomes were assessed using the Musculoskeletal Tumor Society (MSTS93) score (11). $p$-Values of 0.05 were considered statistically significant.

\section{Results}

Over the course of follow-up, seven (35\%) patients experience a recipient site complication (Table II). This included infection $(n=4,27 \%)$, seroma/hematoma $(n=2$, $10 \%$ ), and total flap loss in 1 . The total flap loss occurred in a sural artery rotational flap managed with a free rectus abdominus flap. There were no further complications in this patient. In addition, one patient had venous congestion of the flap, which was salvaged with the use of hyperbaric oxygen therapy. When comparing patients with a flap complication and those without, there was no difference in mean patient age $(61 \pm 16 v s .55 \pm 21$ years, $p=0.52)$, body mass index $\left(29.1 \pm 6.0 v s .31 .3 \pm 6.8 \mathrm{~kg} / \mathrm{m}^{2}, p=0.49\right)$ tumor size $(11 \pm 8 \mathrm{~cm}$ vs. $7 \pm 6 \mathrm{~cm}, p=0.25)$, tumor volume $\left(642 \pm 943 \mathrm{~cm}^{3} v s\right.$. $\left.782 \pm 1,670 \mathrm{~cm}^{3}, p=0.84\right)$, proportion of lower extremity tumors $(\mathrm{n}=4,57 \%$ vs. $\mathrm{n}=10,77 \%, p=0.61)$, proportion of free flaps $(\mathrm{n}=3,43 \%$ vs. $\mathrm{n}=4,31 \%, p=0.65)$, or total radiation dose $(60.2 \pm 2.4$ vs. $59.5 \pm 1.6, p=0.49)$.

Donor site complications occurred in three $(15 \%)$ patients. This included a chest wall seroma in a patient undergoing a free latissimus flap in 1 and a wound dehiscence in a patient undergoing a pedicled ulnar artery flap in 1. One patient underwent a scar revision following harvest of a free transverse rectus abdominus flap.

In addition to the flap complications, four (20\%) patients sustained five radiation-associated fractures. The fracture location included the metatarsals in two, tibia in one, humerus in one and calcaneus in one. In all patients, the bone was the site of the close margin, with two patients having a subperiosteal resection (tibia and calcaneus) and two patients having preservation of the periosteum (metastarsals and humerus). Fractures were treated with intramedullary nailing in one, screw fixation in one, protected weight bearing in one, and one patient refused surgery. Retention of the periosteum did not prevent a radiation-associated fracture (odds ratio=3.0, 95\% confidence intervaI=0.15-59.89, $p=0.99)$.

Following surgery, the mean MSTS93 rating was $75 \pm 11 \%$. There was a trend for patients with tumors of the lower extremity to have improved MSTS93 scores compared to those with upper extremity tumors $(78 \pm 9 \%$ vs. $68 \pm 13 \%$, $p=0.058)$. In addition, there was no difference in the mean MSTS93 score between patients with a free flap compared to those with a pedicled/rotational flap $(78 \pm 12 \%$ vs. $73 \pm 11 \%$, $p=0.33$ ).

At the most recent follow-up, five patients had died of disease, one had died of causes unrelated to their sarcoma, one was alive with metastatic disease, and 13 patients were alive and disease-free. Over the course of the study the 2and 5-year disease-specific survival rates were $78 \%$ and $78 \%$, respectively.

Disease recurrence occurred in eight patients and was defined as isolated metastatic disease in five, local recurrence and metastatic disease in one, and isolated local recurrence in one. The 2- and 5-year local recurrence freesurvival rates were $89 \%$ and $89 \%$, respectively. The local recurrences were treated with re-excision in one patient; in the patient with combined metastatic disease and local recurrence, the local recurrence was asymptomatic and due to the patient's widely metastatic disease, was followed-up by observation only. The local recurrences all occurred in patients without a positive margin. Two patients presented with isolated metastatic disease. For those without metastatic disease at presentation, the 2- and 5-year metastasis-free survival rates were $77 \%$ and $61 \%$, respectively. The location of the metastatic disease included the lungs in three and lymph nodes in two.

\section{Discussion}

Limb salvage surgery with radiotherapy has become the standard treatment option for the majority of extremity softtissue sarcomas. Previous series have shown the use of softtissue flaps to be safe in the setting of preoperative radiotherapy, and the current study examined if the use of flaps was safe in the setting of preoperative radiotherapy with an additional boost of IORT. The results from this study suggest that free and pedicle flaps are safe to perform in the setting of IORT. 
Table I. Characteristics of patients undergoing flap coverage in the setting of intraoperative radiotherapy.

\begin{tabular}{lc}
\hline Characteristic & Value \\
\hline Gender, $\mathrm{n}(\%)$ & $11(55 \%)$ \\
Females & $9(45 \%)$ \\
Males & \\
Age, years & $58 \pm 19$ \\
Mean \pm SD & \\
Body mass index, $\mathrm{kg} / \mathrm{m}^{2}$ & $30.5 \pm 6.7$ \\
Mean \pm SD & \\
Patient comorbidities, $\mathrm{n}(\%)$ & $9(45 \%)$ \\
History of diabetes & $7(35 \%)$ \\
Coronary artery disease & $12(60 \%)$ \\
Hyperlipidemia & $2(10 \%)$ \\
Tobacco use at time of surgery & \\
Tumor-related factors & \\
Maximum tumor dimension, cm & $8 \pm 7$ \\
Mean \pm SD & \\
Tumor volume, cm & \\
Mean \pm SD & \\
Tumor site, $\mathrm{n}(\%)$ & $728 \pm 1,400$ \\
Lower extremity & $14(70 \%)$ \\
Upper extremity & $6(30 \%)$ \\
\hline
\end{tabular}

Previous radiotherapy has been associated with an increased risk of microvascular complications due to the increase of inflammatory cells and up-regulation of cytokines in the endothelium of blood vessels $(12,13)$. In addition, the tissue in a previously radiated field is often fibrotic and the blood vessels in the radiated field are prone to tearing (14). In the current series, an attempt was made to identify recipient vessels outside the IORT field; however, often in the extremity, the vessels are included in the preoperative radiotherapy field. Free flaps have been shown to be safely used in the setting of preoperative radiotherapy $(5,6,9,10)$, and in the current series we had no total flap losses associated with the use of a free flap in the setting of combined preoperative radiotherapy and IORT. The only total flap loss occurred in a patient undergoing a pedicled medial sural artery flap to reconstruct the soft tissue over the distal leg. The use of this type of flap has been associated with a $14 \%$ risk of complications (15), and the flap loss in the current series was salvaged with free flap. In addition in a recent series by Kadle et al., the authors found no difference in the complication rates between the use of a fasciocutaneous and muscle-based flaps in the setting of limb-salvage surgery combined with radiotherapy (6). As such based on the patients in the current series, we feel free tissue flaps are safe to use in the setting of IORT and it is our preference to utilize flaps with long pedicles, such as the latissimus flap, in order to assist with selecting recipient vessels outside the zone of radiation as much as possible.
Table II. Outcome of flap coverage in the setting of intraoperative radiotherapy.

\begin{tabular}{ll}
\hline Complication & Number of patients (\%) \\
\hline All flap-related & $9(45 \%)$ \\
Donor site complication & $2(10 \%)$ \\
Seroma & $1(5 \%)$ \\
Dehiscence & $1(5 \%)$ \\
Scar revision & $1(5 \%)$ \\
Recipient site complication & $7(35 \%)$ \\
Hematoma & $1(5 \%)$ \\
Wound infection & $4(27 \%)$ \\
Seroma & $1(5 \%)$ \\
Flap necrosis/venous congestion & $1(5 \%)$ \\
Total flap loss & $1(5 \%)$ \\
Post-operative fracture & $4(20 \%)$ \\
Progression to amputation & $0(0 \%)$ \\
\hline
\end{tabular}

Intraoperative radiotherapy is thought to provide a benefit in reducing local recurrence in the setting of an unacceptably close margin, by achieving a higher total treatment dose, while reducing complications and toxicity $(7,8)$. Although the dose of radiation is focused on the area of the close margin, wound complications are still common in this patient population (7). In the current study, wound complications and infection were the most common complications, particularly infection $(27 \%)$, which is consistent with a large series evaluating the use of flaps in the setting of preoperative radiotherapy (9).

In addition to wound-healing complications, four patients sustained a radiation-associated fracture. All these fractures occurred within the IORT treatment field, and preservation of the periosteum did not prevent a fracture. Radiotherapy is a known risk factor for fracture, with higher doses of radiotherapy associated with an increased risk of fracture (16). It is important in this patient population to consider prophylactic stabilization when IORT is utilized on bone, as radiation-associated fractures are difficult to manage and often lead to failure of fixation $(17,18)$.

A postoperative boost of external beam radiotherapy is known not to reduce the risk of local recurrence (19), while such IORT is thought to reduce the risk of local recurrence by focusing the boost of radiotherapy directly to the area of concern. In this series of patients, local recurrence occurred in two patients, providing 5-year local recurrence-free survival of $89 \%$. This is similar to other series of planned close margin resections, in addition to planned close and ultimately positive margins to preserve critical structures, without the use of IORT, which reported 5-year local recurrence-free rates of 90-94\% (20). As such, the use of IORT is individualized based on tumor and patient characteristics. 
The results of the current series are not without limitations. The retrospective nature of the study limits the data which can be collected in addition to the analysis we were able to perform. In addition, the overall sample size was small, which was likely secondary to the rarity of softtissue sarcomas. These data were obtained from a single institution and as such there was bias in the treatment of patients who received radiotherapy. Likewise, we are unable to comment on the outcome of patients who potentially might have received IORT but however did not. Although this study provides mid-term follow-up for these reconstructions, it is possible that with longer, follow-up further complications might occur.

Reconstruction following surgery for soft-tissue sarcoma is complex and often involves the use of radiotherapy. Overall, soft-tissue flap reconstruction in the setting of IORT was associated with a high rate of complications, namely wound complications and fractures. Fortunately, total loss of flap is rare, and limb salvage was achieved in all patients.

\section{Conflicts of Interest}

None declared.

\section{Authors' Contributions}

Rachel L. Honig: Drafting of initial and final article, data collection and data analysis.

Meagan E. Tibbo and Katherine E. Mallett: Data collection, data analysis and review of final article. Matthew T. Houdek: Drafting of initial and final article; data collection and analysis; review and editing of final article. Karim Bakri, Safia K. Ahmed, Ivy A. Petersen, Peter S. Rose and Steven L. Moran: Review and editing of final article.

\section{References}

1 Brinkmann EJ, Ahmed SK and Houdek MT: Extremity softtissue sarcoma: Role of local control. Curr Treat Options Oncol 21(2): 13, 2020. PMID: 32025823. DOI: 10.1007/s11864-0200703-9

2 Gronchi A, Colombo C and Raut CP: Surgical management of localized soft tissue tumors. Cancer 120(17): 2638-2648, 2014. PMID: 24752977. DOI: $10.1002 / \mathrm{cncr} .28715$

3 Rosenberg SA, Tepper J, Glatstein E, Costa J, Baker A, Brennan M, DeMoss EV, Seipp C, Sindelar WF, Sugarbaker P and Wesley R: The treatment of soft-tissue sarcomas of the extremities: Prospective randomized evaluations of (1) limb-sparing surgery plus radiation therapy compared with amputation and (2) the role of adjuvant chemotherapy. Ann Surg 196(3): 305-315, 1982. PMID: 7114936. DOI: 10.1097/00000658-198209000-00009

4 O'Sullivan B, Davis AM, Turcotte R, Bell R, Catton C, Chabot P, Wunder J, Kandel R, Goddard K, Sadura A, Pater J and Zee $\mathrm{B}$ : Preoperative versus postoperative radiotherapy in soft-tissue sarcoma of the limbs: A randomised trial. Lancet 359(9325): 2235-2241, 2002. PMID: 12103287. DOI: 10.1016/S0140-6736 (02)09292-9
5 MacArthur IR, McInnes CW, Dalke KR, Akra M, Banerji S, Buchel EW and Hayakawa TJ: Patient reported outcomes following lower extremity soft-tissue sarcoma resection with microsurgical preservation of ambulation. J Reconstr Microsurg 35(3): 168-175, 2019. PMID: 30121052. DOI: 10.1055/s-00381668116

6 Kadle R, Motosko CC, Zakhem GA, Stranix JT, Rapp T and Saadeh PB: Flap reconstruction of sarcoma defects in the setting of neoadjuvant and adjuvant radiation. J Reconstr Microsurg 35(4): 287-293, 2019. PMID: 30357761. DOI: 10.1055/s-0038-1675147

7 Roeder F, Lehner B, Saleh-Ebrahimi L, Hensley FW, Ulrich A, Alldinger I, Mechtersheimer G, Huber PE, Krempien R, Bischof $\mathrm{M}$, Debus J and Uhl M: Intraoperative electron radiation therapy combined with external beam radiation therapy and limb-sparing surgery in extremity soft-tissue sarcoma: A retrospective single center analysis of 183 cases. Radiother Oncol 119(1): 22-29, 2016. PMID: 26651593. DOI: 10.1016/j.radonc.2015.11.014

8 Roeder F, de Paoli A, Saleh-Ebrahimi L, Alldinger I, Bertola G, Boz G, Navarria F, Cuervo M, Uhl M, Alvarez A, Buechler M, Lehner B, Debus J, Calvo FA and Krempien R: Intraoperative electron radiation therapy combined with external beam radiation therapy after gross total resection in extremity soft-tissue sarcoma: A European pooled analysis. Ann Surg Oncol 25(13): 3833-3842, 2018. PMID: 30276647. DOI: 10.1245/s10434-018-6787-9

9 Townley WA, Mah E, O'Neill AC, Wunder JS, Ferguson PC, Zhong $\mathrm{T}$ and Hofer SO: Reconstruction of sarcoma defects following pre-operative radiation: Free tissue transfer is safe and reliable. J Plast Reconstr Aesthet Surg 66(11): 1575-1579, 2013. PMID: 23831122. DOI: 10.1016/j.bjps.2013.06.029

10 Azzi AJ, Zhou S, Safran T, Xu L, Alnaif N and Zadeh T: Vascularized tissue reconstruction in previously irradiated sarcoma defects. Ann Plast Surg 82(1): 89-92, 2019. PMID: 30325838. DOI: $10.1097 /$ SAP.0000000000001652

11 Enneking WF, Dunham W, Gebhardt MC, Malawar M and Pritchard DJ: A system for the functional evaluation of reconstructive procedures after surgical treatment of tumors of the musculoskeletal system. Clin Orthop Relat Res 286: 241246, 1993. PMID: 8425352.

12 Russell NS, Hoving S, Heeneman S, Hage JJ, Woerdeman LA, de Bree R, Lohuis PJ, Smeele L, Cleutjens J, Valenkamp A, Dorresteijn LD, Dalesio O, Daemen MJ and Stewart FA: Novel insights into pathological changes in muscular arteries of radiotherapy patients. Radiother Oncol 92(3): 477-483, 2009. PMID: 19541382. DOI: 10.1016/j.radonc.2009.05.021

13 Weintraub NL, Jones WK and Manka D: Understanding radiationinduced vascular disease. J Am Coll Cardiol 55(12): 1237-1239, 2010. PMID: 20298931. DOI: 10.1016/j.jacc.2009.11.053

14 Mulholland S, Boyd JB, McCabe S, Gullane P, Rotstein L, Brown D and Yoo J: Recipient vessels in head and neck microsurgery: Radiation effect and vessel access. Plast Reconstr Surg 92(4): 628-632, 1993. PMID 8356125. DOI: 10.1097/00 006534-199309001-00011

15 Daar DA, Abdou SA, Cohen JM, Wilson SC and Levine JP: Is the medial sural artery perforator flap a new workhorse flap? A systematic review and meta-analysis. Plast Reconstr Surg 143(2): 393e-403e, 2019. PMID: 30531631. DOI: 10.1097/ PRS.0000000000005204

16 Dickie CI, Parent AL, Griffin AM, Fung S, Chung PW, Catton CN, Ferguson PC, Wunder JS, Bell RS, Sharpe MB and O'Sullivan B: Bone fractures following external beam 
radiotherapy and limb-preservation surgery for lower extremity soft-tissue sarcoma: Relationship to irradiated bone length, volume, tumor location and dose. Int J Radiat Oncol Biol Phys 75(4): 1119-1124, 2009. PMID: 19362782. DOI: 10.1016/ j.ijrobp.2008.12.006

17 Holt GE, Griffin AM, Pintilie M, Wunder JS, Catton C, O'Sullivan B and Bell RS: Fractures following radiotherapy and limb-salvage surgery for lower extremity soft-tissue sarcomas. A comparison of high-dose and low-dose radiotherapy. J Bone Joint Surg Am 87(2): 315-319, 2005. PMID: 15687153. DOI: 10.2106/JBJS.C.01714

18 Sternheim A, Saidi K, Lochab J, O’Donnell PW, Eward WC, Griffin A, Wunder JS and Ferguson P: Internal fixation of radiation-induced pathological fractures of the femur has a high rate of failure. Bone Joint J 95-B(8): 1144-1148, 2013. PMID: 23908434. DOI: 10.1302/0301-620X.95B8.31832
19 Al Yami A, Griffin AM, Ferguson PC, Catton CN, Chung PW, Bell RS, Wunder JS and O'Sullivan B: Positive surgical margins in soft-tissue sarcoma treated with preoperative radiation: Is a postoperative boost necessary? Int J Radiat Oncol Biol Phys 77(4): 1191-1197, 2010. PMID: 20056340. DOI: 10.1016/ j.ijrobp.2009.06.074

20 Gundle KR, Kafchinski L, Gupta S, Griffin AM, Dickson BC, Chung PW, Catton CN, O'Sullivan B, Wunder JS and Ferguson PC: Analysis of margin classification systems for assessing the risk of local recurrence after soft-tissue sarcoma resection. J Clin Oncol 36(7): 704-709, 2018. PMID: 29346043. DOI: 10.1200/ JCO.2017.74.6941

Received October 16, 2020

Revised November 13, 2020

Accepted November 18, 2020 